Int. J. Electrochem. Sci., 13 (2018) $6880-6896$

\title{
Recovery of Submicron-Sized Silicon-Rich Powder from Silicon Sawing Waste for Electrocatalyst of Methanol Electrooxidation
}

\author{
Tzu-Hsuan Tsai ${ }^{l}$ and Yung-Fu $W u^{2, *}$ \\ ${ }^{1}$ Department of Materials and Mineral Resources Engineering, National Taipei University of \\ Technology, Taipei 10608, Taiwan \\ ${ }^{2}$ Department of Chemical Engineering, Ming Chi University of Technology, New Taipei City 24301, \\ Taiwan \\ *E-mail: gausswu@ mail.mcut.edu.tw
}

doi: $10.20964 / 2018.07 .02$

Received: 14 June 2017 / Accepted: 25 July 2017 / Published: 5 June 2018

This study proposed a feasible process for recovering Si-rich powder at room temperature for electrocatalyst applications. The proposed process was successively performed through ultrasonic treatment for particle dispersion, magnetic separation for metal removal, and centrifugation for size classification. The experimental results indicated that the recovered Si-rich powder contained 85 wt.\% $\mathrm{Si}$ and $346 \mathrm{ppm} \mathrm{Fe}$. Subsequently, the recovered powder was directly mixed with carbon to prepare an electrocatalyst for methanol electrooxidation. Our study indicated that the electrocatalytic applications of fine Si powder may be a suitable incentive to recycle Si from sawing waste.

Keywords: Recovery, Silicon, Iron, Sawing Waste, Magnetic Separation, Centrifugation, Electrocatalyst

\section{FULL TEXT}

(C) 2018 The Authors. Published by ESG (www.electrochemsci.org). This article is an open access article distributed under the terms and conditions of the Creative Commons Attribution license (http://creativecommons.org/licenses/by/4.0/). 